\title{
Response to 'No clinical evidence base to support the hygiene hypothesis' by C. P. van Schayck and J. A. Knottnerus
}

\author{
C. Gore*, A. Custovic
} North West Lung Research Centre, Wythenshawe Hospital, Southmoor Road, Manchester M23 9LT, UK

Hypothesis ... an explanation, supposition or assumption, which is put forward in the absence of ascertained facts or causes

The hygiene hypothesis has probably as many friends as it has foes. We feel it should be regarded as an "umbrella theory", encompassing a multitude of more concrete scientific hypotheses, which need to be tested (Fig. 1).

We agree with Professors van Schayck and Knottnerus in that:

1. there are many questions which still need to be answered;

2. not all the previously reported associations have been repeatable;

3. more data from long-term prospective studies is required (although the ongoing birth cohorts have a lot to offer, and data from the first randomised intervention trials is actually available-both will be discussed below);

4. the media laps up any medical theories and preliminary findings, sensationalises them and confuses the issue for the population;

5. ... and certainly with the sentiment thatunfortunately-we have nothing specific to recommend to our patients yet.

However, despite the justified criticism of some of the studies, these have nevertheless contributed to further our understanding of what may be the

*Tel.: +44-161-291-2494; fax: +44-161-291-5057.

E-mail address: cgore@fs1.with.man.ac.uk (C. Gore).

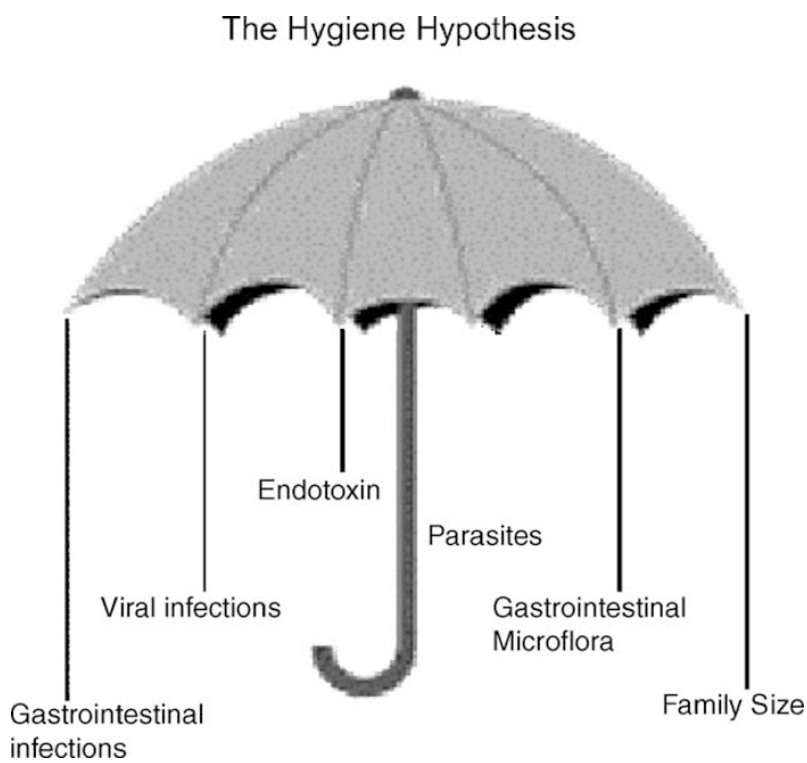

Figure 1 The hygiene hypothesis umbrella.

reason for the steep increase in allergy-and they have provided us with a framework to work with, the hygiene hypothesis.

The epidemiological observations with respect to allergic disease were never designed to give us irrefutable proof of what is happening. What these observations did however was to generate hypotheses. Strachan's observations about family size and cleanliness helped to initiate research into areas, which we might have otherwise neglected [1]. Effect sizes and potential confounders in a population will always be difficult to correct for in 
any one study, be it cross-sectional, longitudinal cohort or intervention. Knowledge about health and disease may well influence the healthcare and lifestyle-choices in the developed world (and this needs to be taken into account), but it is unlikely that large populations of rural Africa are significantly influenced by the western media or by an enhanced awareness of allergic disease. The allergic epidemic is only just starting in the developing world and allows us to test for parameters, which the developed world may already have "outgrown" on the way to a high prevalence of atopic disease $[2,3]$. Improved molecular genetic techniques now facilitate the exploration of gene-environment interactions. Small studies have yielded results on which we can base future larger scale investigations. One example involves the finding that previous infection with Hepatitis A virus (HAV; serological evidence) is protective of atopic disease: these findings have not been confirmed in all studies and one explanation for this could be a recently described genetic marker, determining the immune response to $\mathrm{HAV}$, thus possibly influencing its effect on the development of atopic disease [4-6].

Large birth cohort studies (observational and randomised, placebo-controlled intervention), designed according to specific epidemiological and with high scientific rigour are required $[7,8]$. These need to be based on results from cross-sectional studies, longitudinal studies and small pilot intervention studies. Cross-sectional studies provide good basic data, allowing hypotheses to be refined and developed. The limitation of these studies is that they are confined to a certain population group, usually in a limited geographical area (e.g. endotoxin exposure, allergy development in farming versus non-farming communities $[9,10])$. As atopic diseases usually have their onset in early childhood, the next step is the observational birth cohort study, with the advantages of less reliance on parental recall and the opportunity to measure exposures and physiological parameters, as the children grow older. Currently ongoing, established observational birth cohort studies have greatly increased our understanding of the natural history of atopic disease, allowed the tentative identification of predictors of disease and emphasised the need for well defined objective outcome measures.

Randomised, placebo-controlled intervention trials testing microbial products have been performed. Kalliomaki et al. [11] have acted on the microbiological observation that allergic children have fewer Lactobacilli in their stool samples (assumed to be a consequence of modern life). They first demonstrated in a randomised placebo-controlled, double blind trial that admin- istration of Lactobacillus GG can improve atopic dermatitis in some children and then conducted a randomised, placebo-controlled, double blind primary prevention study $[12,13]$. The latter showed that probiotic administration could prevent the development of atopic dermatitis in some children and this effect persisted to the age of 4 years [14]. Several large primary prevention birth cohorts investigating environmental control and dietary intervention are ongoing at present, but long-term data is still scarce $[15,16]$.

Other randomised placebo-controlled studies have investigated the effect of Mycobacterium vaccae f "vaccination" on established disease $[17,18]$. Recently the first open (pilot) study was published using Trichuris ova in the treatment of inflammatory bowel disease (autoimmune diseases are now being discussed in the light of the hygiene hypothesis as well)-parasites in the treatment of human disease [19]!

The research being carried out under the umbrella of the hygiene hypothesis is by no means perfect and does not as yet allow us to give comprehensive advice to our patients, but the evidence that our modern lifestyle is closely linked to changes in our immune responses to environmental stimuli is growing stronger.

\section{References}

[1] Strachan DP. Hay fever, hygiene, and household size. BMJ 1989;299(6710):1259-60.

[2] Scrivener S, Yemaneberhan $H$, Zebenigus $M$, Tilahun D, Girma S, Ali S, et al. Independent effects of intestinal parasite infection and domestic allergen exposure on risk of wheeze in Ethiopia: a nested case-control study. Lancet 2001;358(9292):1493-9.

[3] van den Biggelaar $A H$, van Ree $R$, Rodrigues LC, Lell B, Deelder AM, Kremsner PG, et al. Decreased atopy in children infected with Schistosoma haematobium: a role for parasite-induced interleukin-10. Lancet 2000;356(9243):1723-7.

[4] Matricardi PM, Rosmini F, Panetta V, Ferrigno L, Bonini S. Hay fever and asthma in relation to markers of infection in the United States. J Allergy Clin Immunol 2002;110(3): 381-7.

[5] Matricardi PM, Rosmini F, Riondino S, Fortini M, Ferrigno $L$, Rapicetta $M$, et al. Exposure to foodborne and orofecal microbes versus airborne viruses in relation to atopy and allergic asthma: epidemiological study. BMJ 2000;320(7232):412-7.

[6] McIntire JJ, Umetsu SE, Macaubas C, Hoyte EG, Cinnioglu C, Cavalli-Sforza LL, et al. Immunology: hepatitis A virus link to atopic disease. Nature 2003;425(6958):576.

[7] Liu AH, Murphy JR. Hygiene hypothesis: fact or fiction? J Allergy Clin Immunol 2003;111(3):471-8.

[8] Kemp A, Bjorksten B. Immune deviation and the hygiene hypothesis: a review of the epidemiological evidence. Pediatr Allergy Immunol 2003;14(2):74-80. 
[9] Riedler J, Braun-Fahrlander C, Eder W, Schreuer M, Waser $M$, Maisch $S$, et al. Exposure to farming in early life and development of asthma and allergy: a cross-sectional survey. Lancet 2001;358(9288):1129-33.

[10] Braun-Fahrlander C, Riedler J, Herz U, Eder W, Waser M, Grize L, et al. Environmental exposure to endotoxin and its relation to asthma in school-age children. N Engl J Med 2002;347(12):869-77.

[11] Kalliomaki M, Kirjavainen P, Eerola E, Kero P, Salminen $S$, Isolauri $E$. Distinct patterns of neonatal gut microflora in infants in whom atopy was and was not developing. J Allergy Clin Immunol 2001;107(1):129-34.

[12] Isolauri E, Arvola T, Sutas Y, Moilanen E, Salminen S. Probiotics in the management of atopic eczema. Clin Exp Allergy 2000;30(11):1604-10.

[13] Kalliomaki M, Salminen S, Arvilommi H, Kero P, Koskinen $P$, Isolauri E. Probiotics in primary prevention of atopic disease: a randomised placebo-controlled trial. Lancet 2001;357(9262):1076-9.

[14] Kalliomaki M, Salminen S, Poussa T, Arvitommi H, Isolaurj follow-up of a randomised placebo-controlled trial. Lancet 2003;361:1869-71.

[15] Gore C, Custovic A. Preventive measures and their effects. Results from cohort studies. Paediatr Respir Rev 2002;3(3):205-18.

[16] Gore C, Custovic A. Primary and secondary prevention of allergic airway disease. Paediatr Respir Rev 2003;4(3): 213-24.

[17] Arkwright PD, David TJ. Effect of Mycobacterium vaccae on atopic dermatitis in children of different ages. $\mathrm{Br} \mathrm{J}$ Dermatol 2003;149(5):1029-34.

[18] Arkwright PD, David TJ. Intradermal administration of a killed Mycobacterium vaccae suspension (SRL 172) is associated with improvement in atopic dermatitis in children with moderate-to-severe disease. J Allergy Clin Immunol 2001:107(3):531-4.

[19] Summers RW, Elliott DE, Qadir K, Urban Jr JF, Thompson R, Weinstock JV. Trichuris suis seems to be safe and possibly effective in the treatment of inflammatory bowel disease. Am J Gastroenterol 2003;98(9):2034-41.

E. Probiotics and prevention of atopic disease: 4-year

Available online at www.sciencedirect.com

science $\boldsymbol{d}$ Directo

Available online at http://www.thepcrj.com 